\title{
Haitianos em Campo Grande, Mato Grosso do Sul: a busca por uma integração humanitária
}

\author{
Haitians in Campo Grande, Mato Grosso do Sul: the search for a humanitarian \\ integration
}

\author{
Haïtiens à Campo Grande, Mato Grosso do Sul: La recherche d'une \\ immigration humanitaire
Haitianos en Campo Grande, Mato Grosso do Sul: la búsqueda de una integración humanitaria

\author{
Andrea Walder Zanatti ${ }^{1}$ \\ José Flávio Rodrigues Siqueira² \\ Robson Gonçalves Félix ${ }^{3}$
}

\begin{abstract}
Recebido em 06/07/2017; revisado e aprovado em 13/09/2017; aceito em 24/09/2017
DOI: http://dx.doi.org/10.20435/inter.v0i0.1651
\end{abstract}

\begin{abstract}
Resumo: O presente artigo apresenta um breve relato histórico sobre a imigração no Brasil desde a Era Vargas, sendo seu principal enfoque a abordagem referente à massificação da chegada de imigrantes haitianos entre os anos de 2010 e 2011 e, especificamente, sobre a integração dos que residem no município de Campo Grande, MS. Para estes foi ofertado um curso de Língua Portuguesa para Estrangeiros, desde março de 2016. Para amparar o estudo, foi aplicado um questionário, além de entrevistas e observação direta com análise dos dados baseados no estudo de caso.
\end{abstract}

Palavras-chave: imigração; haitianos; Língua Portuguesa para estrangeiros.

Abstract: This article presents a brief historical account about immigration in Brazil since Vargas' Era, being your main focus the approach regarding the mass arrival of Haitian immigrants between the years 2010 and 2011 and, specifically, about integration of those who reside in the city of Campo Grande, MS. For these was offered a Portuguese Language Course for Foreigners since March 2016. To support the study, a questionnaire was applied, in addition to interviews and direct observation with data analysis based on the case study.

Keywords: immigration; haitians; Portuguese Language for foreigners.

Résumé: Cet article présente une bref exposé historique relatif à l'immigration au Brésil depuis l'ére Vargas, et son primaire point est la consolidation de l'arrivée massive des immigrants Haïtiens entre les années de 2010 et 2011 et spécifiquement relatif à l'integration de les haïtiens qui habitent la ville de Campo Grande, MS. Pour les haïtiens ont été offert un Cours de Portugais aux Étrangers, depuis mars de 2016. Pour profiter l'étude, on a été appliqué un questionnaire, au delà des interviews et observation direct avec le recherche de données fondées sur l'étude de cas.

Mots-clés: immigration; haïtiens; Langue Portugaise pour étrangers.

Resumen: El presente artículo presenta un breve relato histórico sobre la inmigración en Brasil desde la Era Vargas, siendo su principal enfoque el abordaje referente a la masificación de la llegada de inmigrantes haitianos entre los años 2010 y 2011 y, específicamente, sobre la integración de los que residen en la ciudad de Campo Grande, MS. Para estos, se ofreció un curso de Lengua Portuguesa para Extranjeros, desde marzo de 2016. Para amparar el estudio, se aplicó un cuestionario, además de entrevistas y observación directa con análisis de los datos basados en el estudio de caso.

Palabras clave: inmigración; haitianos; Lengua Portuguesa para extranjeros.

\footnotetext{
${ }^{1}$ Secretaria Municipal de Ensino de Campo Grande, Mato Grosso do Sul, Brasil.

2 Secretaria de Estado de Educação, Campo Grande, Mato Grosso do Sul, Brasil.

${ }^{3}$ Instituto Federal de Educação, Ciência e Tecnologia de Mato Grosso do Sul, Campo Grande, Mato Grosso do Sul, Brasil.
} 


\section{INTRODUÇÃO}

O Brasil é considerado um país multicultural e plurilíngue, pois tem a presença de línguas alóctones (escolas bilíngues), autóctones (indígenas), estrangeiras (migrantes) e de fronteira (predominantemente o espanhol). O reconhecimento da multiculturalidade faz com que se constate a pluralidade de identidades culturais históricas e sociais nas mais diversas localidades de nosso território. Nesse sentido, autores como Featherstone (1997), Canen (1995; 1997), Candau (1997) e Grant (1997) destacam a importância de reconhecimento da fragmentação e pulverização de identidades culturais de classe, raça, gênero, etnia e nacionalidade que necessitam ser levadas em consideração, pois são imprescindíveis à construção de uma sociedade democrática, crítica e participativa.

Mediante a presença da plurietnia e plurilinguismo da sociedade brasileira, a Constituição Federal de 1988, visando assegurar o direito de educação a todos, estabelece em seu Art. 205 que: "A educação, direito de todos e dever do Estado e da família, será promovida e incentivada com a colaboração da sociedade, visando ao pleno desenvolvimento da pessoa, seu preparo para o exercício da cidadania e sua qualificação para o trabalho" (BRASIL, 1988).

Pode-se afirmar que a Constituição Federal se configurou como um instrumento de luta e defesa dos direitos sociais. A possibilidade do rompimento com a desigualdade e exclusão histórica dos sujeitos teve como fundamentos a dignidade da pessoa humana e a promoção do bem de todos, sem discriminação de origem, raça, sexo, cor, idade e quaisquer outras formas de preconceitos.

Nas suas relações internacionais, a Constituição Federal rege a cooperação entre os povos para o progresso da humanidade, bem como a autodeterminação dos povos, e defende, em seu artigo 5, que "todos são iguais perante a lei, sem distinção de qualquer natureza, garantindo-se aos brasileiros e aos estrangeiros, residentes no País, a inviolabilidade do direito à vida, à liberdade, à igualdade, à segurança e à propriedade" (BRASIL, 1988).

Acrescenta-se que, historicamente, o Brasil se constitui como um país de imigrantes, em decorrência da colonização, da escravidão e, após o fim da escravidão, de imigrações desejadas, realizadas no transcorrer do século XX para suprir a falta de mão de obra especializada nas plantações de café, em especial no estado de São Paulo. Nessa época, eram privilegiadas as migrações de ascendentes europeus.

Entretanto, a partir da década de 1930, um conjunto de políticas restritivas foi instituída e dificultou a entrada de imigrantes e refugiados no Brasil. O governo de Getúlio Vargas, de 1930 a 1945, foi reconhecido como sendo rigoroso e restritivo aos imigrantes, considerados como indesejáveis (CARNEIRO, 2003).

Em decorrência, a imigração passou a ser regulada por meio da aprovação da emenda conhecida como a Lei de cotas. Ademais, a Constituição de julho de 1934 determinou restrições à entrada de imigrantes, estipulando, anualmente, para cada nacionalidade, um número máximo de $2 \%$ dos respectivos membros já fixados no Brasil que tivessem imigrado nos últimos 50 anos. Além disso, ficou ainda proibida a concentração de imigrantes em qualquer parte do território (ENDRICA, 2009, p. 176). Essas medidas expressaram uma forte política de branqueamento ou policultura, definida pela seletividade imposta que perdurou até o final da década de 1970, época em que o país estava sob regime militar e o foco nas imigrações era associado à segurança nacional e à mão de obra especializada. 
Observa-se que as migrações internacionais estão presentes em vários períodos de nossa história. Essa realidade intensificou-se nos últimos anos, principalmente pela crescente imigração haitiana, um fenômeno complexo que exige uma interferência direta em contextos políticos e econômicos.

De acordo com o Alto Comissariado das Nações Unidas para os Refugiados (ACNUR, 2005), o Brasil é reconhecido, mundialmente, por seu caráter acolhedor. Desde longa data, considera-se que "o Brasil é um país de asilo e exemplo de comportamento generoso e solidário". Nesse sentido, o Governo brasileiro, com base na Lei 6.815, de 19 de agosto de 1980, regulamentada pelo Conselho Nacional de Imigração (CNIG) por meio da Resolução Normativa n. 97 (BRASIL, 2012), alterada pelas Resoluções Normativas n. 102/2013, 106/2013, 113/2014 e 117/2015, aprovou a concessão de visto permanente a nacionais do Haiti, por razões humanitárias, com prazo de cinco anos e possibilidade de prorrogação.

Conforme a Resolução Normativa 97/2012, consideram-se razões humanitárias aquelas resultantes do agravamento de vida da população haitiana em consequência ao terremoto ocorrido em 12 de janeiro de 2010. Tal terremoto foi um desastre natural que deixou 100 mil mortos e mais de 250 mil pessoas desabrigadas, resultando no surgimento de uma epidemia de cólera em 2011.

Em decorrência desses fatos, a imigração haitiana tem sido considerada a maior no país em cem anos, comparada à imigração de italianos e japoneses no período imperial e primeiros anos da República.

Vale acrescentar que a Convenção de Genebra, obra da Assembleia Geral da ONU de 1950 (Resolução n. 429 V), regula os status legais dos refugiados, consolida instrumentos legais relativos a eles e fornece a codificação de seus direitos em nível internacional. Ao mesmo tempo em que estabelece padrões básicos para o tratamento dessas pessoas, a Convenção de Genebra não impõe limites para que os Estados possam desenvolver esse tratamento, ainda que estabeleça que sua aplicação deva ocorrer sem discriminação por raça, religião, sexo e país de origem.

No Brasil, o artigo 43 da Lei n. 9.474, de 1997, explicita:

[...] considera-se refugiada toda pessoa que, devido a fundados temores de perseguição em razão de raça, religião, nacionalidade, pertencimento a grupo social específico ou opinião política não pode ou não quer regressar a ele; ou devido a grave e generalizada violação de direitos humanos, é obrigado a deixar seu país de nacionalidade para buscar refúgio em outro país. (BRASIL, 1997).

O Haiti possui aproximadamente 11 milhões de habitantes, que sofrem com graves problemas em decorrência da falta de serviços básicos, tais como: água, energia elétrica, comida e educação. Vale salientar, ainda, que desde 2004, a convite das Nações Unidas, o exército brasileiro comanda a Missão de Estabilização das Nações Unidas no Haiti (MINUSTAH). Instituída pela Resolução n. 1.542 em 30 de abril de 2004 pelo Conselho de Segurança ${ }^{4}$, a Minustah conta com a participação de tropas de mais 15 países.

Consoante aos dados da United Nations Development Programme (UNDP), 75\% da população vive em extrema pobreza, e cerca de $80 \%$ com uma renda de menos de dois dólares por dia. Mais da metade da população ativa está subempregada ou desempregada. A expectativa de vida para os homens é de menos de 55 anos, e para as mulheres é de 58 anos. Observa-se que,

\footnotetext{
${ }^{4}$ http://www.un.org/es/peacekeeping/missions/minustah/
} 
[...] há um desenvolvimento progressivo que se acentua após o terremoto de 2010, como consequência, abrindo canais legais para acolher haitianos no Brasil. Também instituições brasileiras não governamentais aprofundam serviços humanitários visando o desenvolvimento do povo haitiano. (ZAMBERLAN et al., 2014, p. 28)

Acrescenta-se que o Haiti é uma das poucas ex-colônias francesas nas Américas. Por meio da Constituição haitiana de 1987, o crioulo, língua vernácula falada por 100\% da população, junto com o francês, falado por aproximadamente $10 \%$ da população, tornaram-se línguas co-oficiais - oficializando o bilinguismo no Estado.

Mas o crioulo, como aponta Rodrigues (2008 , p. 5), é visto como uma língua sem status (língua baixa) em relação ao francês (língua alta), pois:

[...] Durante muito tempo sustentou-se a tese de que o crioulo seria apenas um patois, um dialeto oriundo do francês, inapto a expressar conceitos abstratos, científicos e, por isso, indigno de reconhecimento, devendo se limitar ao domínio musical, às piadas ou às conversas informais. Esta percepção do crioulo como um patois - embora em escala bem menor - ainda se encontra em todos os níveis da sociedade. O senso comum acusa equivocadamente $o$ crioulo de ser desprovido de uma estrutura gramatical. Além disso, reprova-se-Ihe favorecer o isolamento de um país já por demais mal visto pela opinião pública internacional, como se fosse uma ideia estapafúrdia utilizar o crioulo numa América sobretudo hispanófona e anglófona. (RODRIGUES, 2008, p. 5)

Dessa maneira, o francês (língua alta) é utilizado nas escolas, igrejas, universidades, discursos políticos, enquanto o crioulo (língua baixa) é utilizado no dia a dia, nas relações inferiores. Emprega-se assim a diglossia ${ }^{5}$, que, para Rodrigues (2008, p. 69), reflete "uma estratificação social estável, uma sociedade dividida em castas relativamente estanques às quais correspondiam funções e status rigidamente definidos". Ressalta-se que tal situação diglóssica dificulta a comunicação dos haitianos em solo brasileiro.

Enquanto as barreiras comunicativas dificultam o acesso a serviços básicos, um dos principais fatores da imigração, em geral, é a falta desses serviços, de trabalho, de liberdade de expressão e fé religiosa, muitos destes enfrentados pelos haitianos, que se sentem atraídos pelo Brasil, um país de clima agradável e amplas possibilidades.

Entre os anos de 2010 e 2011 - época de maior imigração compulsória, o Brasil passava por um período econômico positivo, com oferta de oportunidades de trabalho, principalmente na área da construção civil, além de ser considerado um país acolhedor em termos religiosos.

Todavia destaca-se que o imigrante deixa para trás um lastro de amizades e expectativas, afora o universo sociocultural que exprimia em língua materna. Registra-se que, segundo o Censo Escolar de $2013^{6}$, as escolas públicas brasileiras atenderam 60.372 estudantes estrangeiros.

Entende-se com isto que a preocupação se concentra, também, na democratização do saber, aquele saber que inclui o domínio mais amplo e aprofundado do estudo da Língua Portuguesa, pois na atualidade vivemos a Era dos Direitos, a exemplo da Declaração Universal dos Direitos Linguísticos (DUDL) ${ }^{7}$. Mas, para a igualdade ser real aos estrangeiros, ela há de ser relativa, res-

\footnotetext{
${ }^{5}$ Diglossia - situação de bilinguismo ou bidialetalismo, dicionário Houaiss.

${ }^{6}$ Fonte: http://portal.inep.gov.br/basica-censo

7 Proclamada em junho de 1996, em Barcelona, tendo como pressupostos a Declaração Universal dos Direitos do Homem (1948), o Pacto Internacional dos Direitos Civis e Políticos (1966), Declaração sobre os Direitos de Pessoas Pertencentes a Minorias Nacionais ou Étnicas, Religiosas e Linguísticas (1992), a Carta Europeias sobre as Línguas Regionais ou Minoritárias (1992), Declaração de Santiago de Compostela (1995), Declaração do Recife de 09/10/1987, Declaração Universal dos Direitos Coletivos dos Povos,
} 
peitando os conhecimentos já adquiridos pelos estudantes estrangeiros e sua prática social inicial. Além disso, a complexidade do processo de ensino e aprendizagem de uma Língua Estrangeira, no caso a Língua Portuguesa, é bastante significativa, tendo em vista que "[...] quando se aprende uma nova língua, não se aprende apenas uma nova técnica - palavras, sons, regras - mas se aprende também a recortar o mundo de forma diferente" (BITTENCOURT, 1997, p. 92).

A partir desse recorte teórico, constata-se que os imigrantes, em especial os haitianos, buscam no Brasil novas oportunidades para auxiliarem a subsistência de seus familiares. Segundo o Relatório de Gestão do Exercício de $2016^{8}$ da Polícia Federal, publicado em 2017:

No ano de 2016, o Departamento de Migrações e a Secretaria Nacional de Justiça realizaram uma série de iniciativas no intuito de promover os direitos e a integração de migrantes e refugiados no Brasil. No que tange à oferta de serviços, foram realizados repasses financeiros no âmbito dos convênios para a implantação de dois centros de referência e acolhida a migrantes e refugiados (CRAls), um no município de Porto Alegre/RS e outro em Florianópolis/SC. Também foi lançado Edital de Chamamento Público para que organizações da sociedade civil apresentem projetos que fomentem a integração de migrantes e refugiados. Complementarmente, foram realizados repasses de recursos para organizações da sociedade civil ofertarem cursos de português para migrantes e refugiados. Em novembro, por intermédio do Despacho no 1.921/2016 GAB/SNJ, foi prorrogado, por seis meses, o prazo para que os cidadãos haitianos beneficiários de permanência em território nacional por razões humanitárias apresentem-se à autoridade competente para a realização de seus registros, para efeitos de regularizando de suas situações migratórias no País.

Além disso, o Relatório também pontuou que:

Em relação a ações específicas para a garantia dos direitos e integração de refugiados no Brasil, destaca-se as seguintes iniciativas do Comitê Nacional para os Refugiados- CONARE, em 2016: a) disponibilização de turmas para migrantes e refugiados no curso PRONATEC Língua Portuguesa e Cultura Brasileira para Estrangeiros, em parceria com o Instituto Federal do Rio de Janeiro (IFRJ) e Instituto Federal de Brasília (IFB); b) lançamento, em abril, juntamente com o SEBRAE Nacional e SEBRAE-SP, o projeto Refugiado Empreendedor, oferecendo cursos gratuitos de empreendedorismo a refugiados; c) estabelecimento, junto à Universidade de Ottawa, Canadá, da Iniciativa Conjunta para Fortalecer o Patrocínio Privado de Refugiados; d) desburocratização das solicitações de autorização de viagens, por intermédio da aprovação da Resolução Normativa 23, de 30 de setembro de 2016, a qual "estabelece procedimentos de solicitação de passaporte e viagem ao exterior para pessoas refugiados e solicitantes de refúgio". As iniciativas para atualização da legislação migratória brasileira também merecem destaque entre as ações realizadas em 2016, seja em termos pontuais, a exemplo do Decreto no 8.757, de 10 de maio de 2016, seja em termos mais abrangentes, com o avanço da tramitação, no Congresso Nacional, do projeto de lei que estabelecerá uma nova legislação sobre o tema, alinhando-a aos preceitos da Constituição Federal de 1988.

Cabe destacar que o Brasil, até maio de 2017, não possuía uma legislação adequada para o atendimento dessa nova demanda de estrangeiros, tanto que era um dos poucos países que não possuíam um serviço de imigração, pois cabia à Polícia Federal grande parte do processamento dos pedidos de residência e de refúgio, de caráter eminentemente administrativo.

Barcelona (1990), Declaração Final da Assembleia Geral da Federação Internacional dos Professores de Línguas Vivas , Hungria.

${ }^{8}<$ http://www.pf.gov.br/institucional/acessoainformacao/auditorias/prestacao-de-contas/prestacao-de-contas-2016/relatoriode-gestao-consolidado.pdf/view> 
Em 24 de maio de 2017 foi publicada a Lei n. 13.445, instituindo a Lei de Migração. De acordo com o artigo n. 125, a referida Lei entrará em vigor após decorridos 180 (cento e oitenta) dias de sua publicação oficial.

Destaca-se que a Lei de Migração, diferentemente da legislação imigratória da Era Vargas, desfaz a ideia de que o imigrante é uma ameaça à segurança nacional e estabelece os direitos e deveres dos imigrantes e visitantes. Dentre as garantias de condições de igualdade aos nacionais, os imigrantes terão o direito à liberdade, à segurança, inviolabilidade do direito à vida, assim como acesso aos serviços públicos como os de saúde e educação. Além disso, poderão exercer cargo, emprego ou função pública, conforme estabelecido em edital, exceto de concursos reservados a brasileiros natos.

Mediante ao exposto, no gráfico abaixo, observa-se que houve um aumento significativo de imigrações nos últimos anos.

Gráfico 1-Número de imigrantes registrados pela Polícia Federal - por ano

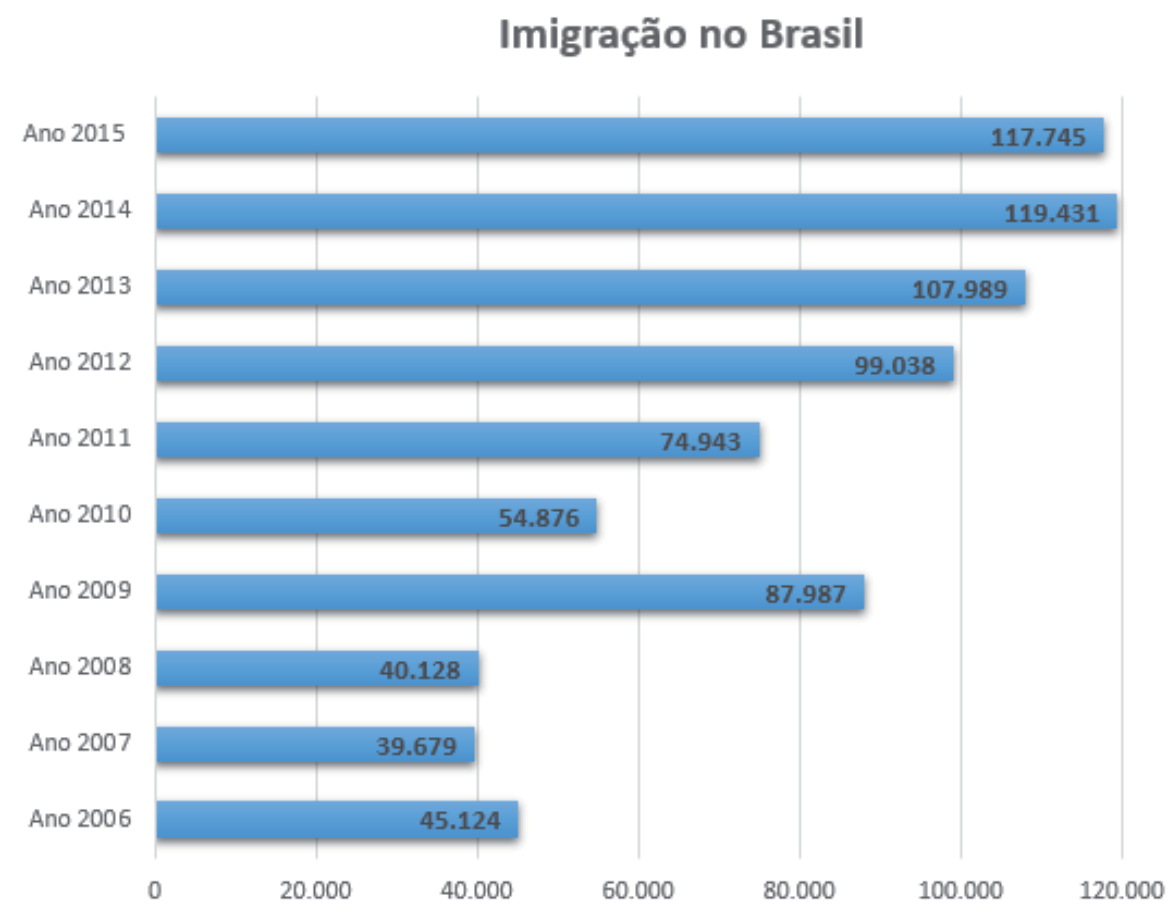

Fonte: Polícia Federal

A partir desses dados, o Ministério Público do Trabalho do estado de Mato Grosso do Sul ${ }^{9}$, ao constatar que em Campo Grande, capital do estado, no ano de 2015 residiam aproximadamente 100 imigrantes haitianos, ofertou para 50 haitianos curso de Língua Portuguesa, de dezembro de 2015 a fevereiro de 2016, nas comunidades dos bairros Rita Vieira e Vila Progresso. Posteriormente, visando à continuidade na oferta do curso, o Ministério Público solicitou à Secretaria de Estado de Educação (SED/MS) que acolhesse essas pessoas por meio da oferta de curso de Português para estrangeiros, o que foi executado pelo Centro Estadual de Línguas e Libras (CEL/MS) a partir de março de 2016.

\footnotetext{
${ }^{9}$ http://www.prt24.mpt.mp.br/informe-se/noticias-do-mpt-ms/449-curso-de-portugues-para-haitianos-encerra-com-expectativa de-melhoria-de-trabalho
} 
Com base nessas informações, iniciou-se um Estudo de Caso, com observação direta e aplicação de questionários e entrevistas. Assim, este artigo propõe descrever e analisar as dificuldades, vivências e anseios da população de imigrantes haitianos residentes no município de Campo Grande que participaram do curso de Português para estrangeiros. Os dados aqui apresentados resultam de uma pesquisa realizada entre os meses de março a dezembro de 2016. Na ocasião, os questionários foram aplicados em Língua Portuguesa, tendo como intérprete/ tradutor, aos imigrantes que não possuíam domínio da Língua Portuguesa, o professor regente que é fluente em crioulo e francês.

Em termos metodológicos, a opção pelo estudo de caso se ampara nos argumentos de Goldenberg (2004, p. 34), para quem:

O estudo de caso não é uma técnica específica, mas uma análise holística, a mais completa possível, que considera a unidade social estudada como um todo, seja um indivíduo, uma família, uma instituição ou uma comunidade, com o objetivo de compreendê-los em seus próprios termos. O estudo de caso reúne o maior número de informações detalhadas, por meio de diferentes técnicas de pesquisa, com o objetivo de apreender a totalidade de uma situação e descrever a complexidade de um caso concreto.

Por essa perspectiva, a abordagem realizada no presente estudo buscou identificar e analisar diferentes aspectos que se consolidaram, na perspectiva dos imigrantes haitianos, como fundamentais no processo de transição e adaptação à nova realidade dessa população em território brasileiro, na região centro-oeste do país, entre a comunidade sul-mato-grossense residente na capital do estado.

\section{O MUNICÍPIO DE CAMPO GRANDE, MS, E O ATENDIMENTO HUMANITÁRIO DE ESTRANGEIROS}

O município de Campo Grande, segundo dados do Instituto Brasileiro de Geografia e Estatísticas (IBGE) ${ }^{10}$, possuía, em 2016, uma população estimada de 863.982 pessoas. Seu PIB per capita, em 2014, foi de $\mathrm{R} \$ 28.349,62$. As religiões predominantes são: católica, evangélica e espírita. Com relação à educação, os estudantes dos anos iniciais da rede pública do município tiveram nota média de 5.4 no IDEB, para os anos iniciais, e de 4.8 para os anos finais, em 2015.

Nesse prisma, o Centro Estadual de Línguas e Libras (CEL Professor Fernando Peralta Filho) foi criado em 22 de novembro de 2011, por meio do Decreto n. 13.301 em atendimento à Lei n. 11.161 , de 5 de agosto de 2005. O CEL constitui-se em um espaço fundamental para a capacitação linguística de estudantes e professores da Rede Estadual de Ensino e cidadãos de Mato Grosso do Sul.

O CEL surge não somente da aplicação da lei citada, mas da necessidade de interação social por meio do plurilinguismo e, consequentemente, da melhoria do processo de ensino e aprendizagem no município de Campo Grande. Tal melhoria possui fundamentação na abordagem plurilinguística, para a qual a construção da competência comunicativa se dá à medida que a experiência pessoal de cada um se expande, em seu contexto cultural, da língua falada em casa para a da sociedade e, em seguida, para a língua de outros povos conforme o Quadro Europeu Comum de Referência para as Línguas (QECR, 2001, p. 23).

Por ser função do Estado zelar por ações de inclusão social, articuladas a um ensino e aprendizagem que resultem na formação de indivíduos capazes de assumir uma postura crítica e

\footnotetext{
${ }^{10}$ https://cidades.ibge.gov.br/v4/brasil/ms/campo-grande/panorama
} 
autônoma frente ao mundo, e por entender que a dificuldade de aprender a Língua Portuguesa interfere diretamente na autonomia de cada estrangeiro e prejudica sua integração social, a Secretaria de Estado de Educação SED/MS, por meio do Centro Estadual de Línguas e Libras (CEL) passou a ofertar, desde março de 2016, curso de Língua Portuguesa ${ }^{11}$ aos haitianos, para romper a barreira de comunicação e expressão, considerando que o domínio da língua tem estreita relação com a possibilidade de plena participação social.

\section{DIFERENCIAÇÃO ENTRE SEGUNDA LÍNGUA (SL OU L2) DE LÍNGUA ESTRANGEIRA (LE): UMA ANÁLISE DO DISCURSO}

Entende-se como romper a barreira de comunicação e expressão, a linguagem que busca fazer sentido enquanto trabalho simbólico ao sujeito que procura pela compreensão/aquisição de uma Língua Estrangeira. A abordagem dessa compreensão/aquisição passa pela análise do discurso. Nesse contexto, corrobora-se com Orlandi (2003, p. 15-6) no sentido de que:

Análise de Discurso não trabalha com a língua enquanto um sistema abstrato, mas com a língua no mundo, com maneiras de significar, com homens falando, considerando a produção de sentidos enquanto parte de suas vidas, seja enquanto sujeitos seja enquanto membros de uma determinada forma de sociedade. Levando em conta o homem na sua história, considera os processos e as condições de produção da linguagem, pela análise da relação estabelecida pela língua com os sujeitos que a falam e as situações em que se produz o dizer.

Dotada de significados que não se limitam ou se explicam em si mesmos, a análise do discurso compreende a necessária articulação dos sujeitos em seu contexto histórico, razão pela qual a compreensão do objeto do presente estudo perpassa o reconhecimento de sua constituição e expressão concreta.

A análise do discurso, do ponto de vista das ciências da linguagem, não é experimental, mas empírico-dedutiva. Isto significa que o analista parte de um material empírico, a linguagem, que já está configurada numa certa substância semiológica (verbal). É esta configuração que o analista percebe, podendo manipulá-la através da observação das compatibilidades e incompatibilidades das infinitas combinações possíveis, para determinar recortes formais, simultaneamente às categorias conceituais que Ihes correspondem. Uma análise do discurso, deve, pois, determinar quais são seus objetivos em relação com o tipo de objeto construído, e qual é a instrumentalização utilizada, de acordo com o procedimento escolhido'. (CHARAUDEAU, 2005, p. 20).

Sob tais pressupostos metodológicos, os questionários utilizados nesse estudo analisaram o contexto social e cultural no qual os haitianos estão inseridos, para considerar sua produção de sentido. Acrescenta-se que além da análise do discurso, o estudo de caso também averiguou se e como as trocas linguísticas relacionaram-se com o poder simbólico que se impõe por meio das estruturas de produção e reprodução do meio, pois eles se encontram em posição social diferenciada.

Todo ato de fala e, de um modo geral, toda ação é uma conjuntura, um encontro de séries causais independentes: de um lado, as disposições, socialmente modeladas, do habitus linguístico, que implicam uma certa propensão a falar e a dizer coisas determinadas (interesse expressivo), definida ao mesmo tempo como capacidade linguística de engendramento infi-

\footnotetext{
${ }^{11}$ http://www.sed.ms.gov.br/?p=5592
} 
nito de discursos gramaticalmente conformes e como capacidade social que permite utilizar adequadamente essa competência numa situação determinada; do outro, as estruturas do mercado linguístico, que se impõem como um sistema de sanções e de censuras específicas. (BOURDIEU, 2008, p. 24).

Em conformidade com o aporte teórico proposto por Bourdieu (2008, p. 24), a coleta de dados buscou identificar as correlações entre as manifestações particulares dos habitus linguísticos do público pesquisado com o contexto em que foram produzidos. Nessa perspectiva, cabe compreender e distinguir Segunda Língua (SL ou L2) de Língua Estrangeira (LE).

Segundo Almeida Filho (2004), Língua Estrangeira é outra língua dentro de outra cultura e país pelo qual o indivíduo desenvolve um interesse particular ou institucionalizado em conhecê-la, enquanto Segunda Língua é uma Língua não-materna que se sobrepõe a outra, que não circula ou circula setorialmente com restrições.

Para Grannier (2002), os brasileiros que têm como Primeira Língua uma das mais de 180 línguas indígenas ou a Língua Brasileira de Sinais (LIBRAS), a Língua Portuguesa é a nova Língua - Segunda Língua.

Torna-se evidente a complexidade do ensino de uma Língua Estrangeira, pois se trata de uma linguagem compreendida como um conjunto de práticas sociais, cujo foco estará nos textos e circunstâncias que eles serão utilizados. Pode-se afirmar que:

[...] a gramática define apenas muito parcialmente o sentido, e não é na relação com um mercado que se opera a determinação completa do significado do discurso. Uma parte, e não a menor, das determinações que constituem a definição prática do sentido se transfere de fora automaticamente para o discurso. (BOURDIEU, 2008, p. 24).

Para além da leitura de signos dotados de sentido em si mesmos, a linguagem representa uma das formas de materialização da leitura de mundo, e por ela se constitui. No caso em estudo, o curso foi ofertado apenas na modalidade presencial, pois a principal preocupação foi a integração da comunidade haitiana por meio da apropriação da Língua Portuguesa. Portanto os critérios estabelecidos de frequência e conceito foram diferenciados em relação aos demais cursos de Língua Estrangeira ofertados pelo CEL/MS, pois, conforme o resultado apresentado pelo questionário aplicado aos cursistas, descritos abaixo, não havia homogeneidade de conhecimentos entre eles.

Observou-se que a maioria dos respondentes possuía apenas o equivalente ao ensino fundamental. Além disso, os princípios que nortearam a avaliação do curso ultrapassaram a preocupação com o desempenho ou rendimento escolar, buscando analisar o significado mais amplo de formação pessoal e profissional dos cursistas. Logo, os cursistas foram avaliados por meio de conceitos (ótimo, bom e regular).

Desde o início de suas atividades, em março de 2016, o curso de Língua Portuguesa para estrangeiros do CEL/MS realizou seu atendimento em conformidade com o levantamento de concentração da comunidade haitiana pelo Comitê Estadual para os Refugiados e Migrantes em Mato Grosso do Sul e pelo Ministério Público. Diante da constatação de que o público-alvo residia principalmente nos bairros Rita Vieira e Vila Progresso, a Secretaria de Estado de Educação cedeu duas salas de aula nas escolas estaduais João Carlos Flores, situada no bairro Rita Vieira, e Orcírio Thiago de Oliveira, presente no bairro Vila Progresso.

As aulas foram ministradas duas vezes na semana, das $19 \mathrm{~h}$ às $21 \mathrm{~h}$, e a comunidade haitiana recebeu uniforme da Secretaria de Estado de Educação (SED/MS), além de também te- 
rem direito à merenda. No processo de matrículas, que em 2016 ocorreu no mês de fevereiro, inscreveram-se 25 haitianos/alunos em cada turma/escola. No ano de 2017, as aulas tiveram seu início, novamente em fevereiro.

\section{ESTUDO DE CASO}

Cabe destacar que, antes da observação direta, cujo objetivo foi analisar o enfoque empregado durante as aulas (práticas sociais, textos e circunstâncias), tornou-se necessário conhecer a realidade desse público. Para tanto, foi aplicado um questionário, a fim de colher dados de informações pessoais para constatar: quem são essas pessoas? Como se expressam? O que fazem? Quais são seus conhecimentos? Quais são seus desejos e expectativas? Quais projetos de vida manifestam?

Em virtude disso, o questionário visou detectar os problemas que os envolveram quando da chegada ao Brasil; o grau de escolaridade; profissão; religião; línguas que dominam; estado de saúde; a violência acometida ou não, e o tipo de violência acometida; o interesse de permanência no Brasil; o interesse de continuidade nos estudos; o interesse em participar em cursos profissionalizantes, enfim, dados considerados importantes para o conhecimento das reais necessidades para a busca das possíveis soluções por meio da Língua Portuguesa, conforme dados tabulados abaixo:

Tabela 1 - Gênero dos cursistas entrevistados

\begin{tabular}{|c|c|c|}
\hline Gênero & Masculino & Feminino \\
\hline Quantidade & 19 & 18 \\
\hline
\end{tabular}

Fonte: autores da pesquisa

Observa-se, pela tabela 1, que a quantidade de cursistas durante a aplicação do questionário foi praticamente equivalente. A interação em sala de aula pelas mulheres era mínima, sendo notável elas se apresentarem quietas e tímidas. O professor da turma, que é nativo, ao ser questionado sobre a pouca interação das cursistas, esclareceu que isso é uma característica cultural, que as mulheres quase não se manifestam, nem mesmo quando possuem dúvidas.

Tabela 2 - Estado civil dos cursistas entrevistados

\begin{tabular}{|l|c|}
\hline \multicolumn{1}{|c|}{ Estado civil } & Quantidade de cursistas \\
\hline Casado(a) & 21 \\
\hline Solteiro(a) & 9 \\
\hline União estável & 5 \\
\hline Divorciado(a) & 1 \\
\hline Separado(a) & 1 \\
\hline
\end{tabular}

Fonte: autores da pesquisa

A maioria dos homens casados declarou possuir família no Haiti, e que vieram ao Brasil em busca de uma vida melhor; a intenção, segundo eles, é voltar para seu país de origem ou trazer a família para o Brasil. As mulheres, por outro lado, estão junto com os respectivos maridos. 
Tabela 3 - Quantidade de filhos dos cursistas entrevistados

\begin{tabular}{|l|c|}
\hline \multicolumn{1}{|c|}{ Filhos } & Quantidade de cursistas \\
\hline Seis filhos & 2 \\
\hline Quatro filhos & 1 \\
\hline Três filhos & 11 \\
\hline Dois filhos & 7 \\
\hline Um filho & 8 \\
\hline Não tem & 8 \\
\hline
\end{tabular}

Fonte: autores da pesquisa

Tabela 4 - Local onde residem os filhos dos cursistas entrevistados

\begin{tabular}{|l|c|}
\hline \multicolumn{1}{|c|}{ País } & Quantidade de cursistas \\
\hline Haiti & 21 \\
\hline República Dominicana & 7 \\
\hline Brasil & 1 \\
\hline
\end{tabular}

Fonte: autores da pesquisa

Apenas uma família trouxe o filho para o Brasil. Os demais estão com parentes no Haiti, tais como avós, tias ou esposas que ainda permanecem no país de origem, ou na República Dominicana, conforme consta nas tabelas 3 e 4 . Ressalta-se que muitos haitianos, pelos relatos, também buscaram refúgio no país vizinho.

Tabela 5 - Religião dos cursistas entrevistados

\begin{tabular}{|l|c|}
\hline \multicolumn{1}{|c|}{ Religião } & Quantidade de cursistas \\
\hline Evangélico (a) & 23 \\
\hline Católico (a) & 8 \\
\hline Batista & 2 \\
\hline Espírita & 2 \\
\hline Sem resposta & 2 \\
\hline
\end{tabular}

Fonte: autores da pesquisa

Os evangélicos e católicos são a maioria entre os haitianos entrevistados, segundo a tabela 5. Acrescenta-se que o grupo que reside no bairro Rita Vieira recebeu/recebe acolhimento da/na Paróquia Divino Espírito Santo ${ }^{12}$; eles costumam se reunir aos sábados, no período vespertino. A Paróquia realiza doações de alimentos e roupas, por meio da comunidade.

Tabela 6 - Grau de instrução dos cursistas entrevistados

\begin{tabular}{|l|c|}
\hline \multicolumn{1}{|c|}{ Escolaridade } & Quantidade de cursistas \\
\hline Ensino fundamental incompleto & 15 \\
\hline Ensino médio incompleto & 12 \\
\hline Ensino fundamental completo & 4 \\
\hline Ensino médio completo & 3 \\
\hline Superior incompleto & 3 \\
\hline
\end{tabular}

Fonte: autores da pesquisa

\footnotetext{
12 http://www.correiodoestado.com.br/arte-e-cultura/tempo-de-reconstrucao-em-busca-de-um-recomeco-o-haiti-eaqui/289336/
} 
De acordo com a tabela 6, os entrevistados, em sua maioria, possuem ensino fundamental e médio incompletos- equivalentes ao do Brasil. Observou-se, durante o estudo, que a falta de escolaridade da maioria dos haitianos dificultou o processo de aprendizagem da Língua Portuguesa, e o professor precisou usar uma metodologia diferenciada para os grupos em decorrência da dificuldade apresentada. Foram adotados diversos materiais de apoio, dentre eles a Apostila Crioulo Haitiano - Português, Ann Pale Potigè ${ }^{13}$, o livro Pode Entrar - Português do Brasil para refugiadas e refugiados ${ }^{14}$, dentre outros.

Ressalta-se que o enfoque principal do curso foi propiciar aos haitianos a possibilidade de comunicação deles com as demais pessoas. Por isso, o uso de uma metodologia e avaliação diferenciadas aos demais cursos ofertados pelo Centro de Língua, MS.

Tabela 7 - Profissão exercida, no Brasil, pelos cursistas entrevistados

\begin{tabular}{|l|c|}
\hline \multicolumn{1}{|c|}{ Profissão } & Quantidade de cursistas \\
\hline Pedreiro & 11 \\
\hline Serviços gerais & 9 \\
\hline Costureira & 2 \\
\hline Camareira & 2 \\
\hline Carpinteiro & 3 \\
\hline Cabelereira & 1 \\
\hline Cozinheira & 2 \\
\hline Servente & 3 \\
\hline Marceneiro & 1 \\
\hline Estudante & 2 \\
\hline Eletricista & 1 \\
\hline
\end{tabular}

Fonte: autores da pesquisa

Entre os homens, conforme consta na tabela 7, a maioria trabalha na construção civil como pedreiros, e as mulheres em serviços gerais em casas e empresas. Dentre os homens, o interesse deles é crescer profissionalmente na área da construção civil, como mestres de obras ou engenheiros, e as mulheres têm por interesse fazer cursos profissionais na área de corte e costura e gastronomia.

Observou-se durante o curso que, apesar de terem sido bem acolhidos pela comunidade local, o maior desejo deles é retornar para o país de origem, ainda que eles tenham demonstrado consciência de que aqui as condições financeiras são melhores.

Tabela 8 - Língua falada pelos cursistas entrevistados

\begin{tabular}{|l|c|}
\hline \multicolumn{1}{|c|}{ Língua falada } & \multicolumn{1}{c|}{ Quantidade de cursistas } \\
\hline Crioulo - Francês - Português & 9 \\
\hline Crioulo - Espanhol - Português & 7 \\
\hline Crioulo - Francês & 6 \\
\hline Crioulo - Francês - Espanhol - Português & 3 \\
\hline Crioulo - Espanhol - Inglês - Português & 3 \\
\hline Crioulo - Português & 3 \\
\hline Francês - Espanhol - Inglês & 2 \\
\hline Crioulo - Francês - inglês - Português & 2 \\
\hline Crioulo - Francês - Espanhol - Inglês- Português & 2 \\
\hline
\end{tabular}

Fonte: autores da pesquisa

\footnotetext{
${ }^{13} \mathrm{https}$ //haiti.iom.int/bvac/sites/default/files/pdf/cartilha-kreyol-vocabulario.pdf

${ }^{14}$ http://www.acnur.org/t3/fileadmin/Documentos/portugues/Publicacoes/2015/Pode_Entrar.pdf
} 
Observou-se, durante as aulas, que a comunicação entre os cursistas era, exclusivamente, em crioulo. Todos marcaram mais de uma língua falada, entretanto o conhecimento da maioria era superficial em relação as línguas relacionadas na tabela 8, sendo identificado que eles conseguem se comunicar, mas em um nível básico.

Tabela 9 - Quais são os interesses e motivações dos cursistas em aprender a Língua Portuguesa

\begin{tabular}{|l|c|}
\hline \multicolumn{1}{|c|}{ Aprender a Língua Portuguesa } & Quantidade de cursistas \\
\hline Fazer faculdade, crescer profissionalmente e ajudar a família & 17 \\
\hline Fazer faculdade & 8 \\
\hline Sem resposta & 6 \\
\hline Estudar e ter um emprego melhor & 3 \\
\hline Trabalhar & 2 \\
\hline Crescer na vida & 1 \\
\hline
\end{tabular}

Fonte: autores da pesquisa

Conforme descrito anteriormente, o maior desejo dos cursistas é retornar para o seu país de origem. Em conversa com o professor do curso, após a análise das respostas da tabela 9, ele disse que os cursistas ficaram envergonhados em falar que querem aprender a língua apenas para se comunicar, não para permanecer no país, dar continuidade aos estudos e/ou até cursar uma faculdade.

Tabela 10 - Os cursistas entrevistados sofreram algum tipo de violência no Brasil

\begin{tabular}{|l|c|}
\hline Não sofreu violência & 35 \\
\hline Violência policial & 1 \\
\hline Assalto a mão armada em frente de casa & 1 \\
\hline
\end{tabular}

Fonte: autores da pesquisa

Em relação à tabela 10, a pergunta refere-se desde a chegada ao Brasil, não em Campo Grande, MS. Dois cursistas responderam que sofreram algum tipo de violência, sendo policial e assalto a mão armada. No geral, eles consideram a cidade e o bairro em que residem tranquilos em relação à convivência do dia a dia.

\section{CONSIDERAÇÕES FINAIS}

De acordo com Gadotti (2000), "falar em perspectivas é falar de esperança no futuro". A perspectiva de romper com as barreiras comunicativas que dificultam o acesso aos serviços básicos, à religiosidade, à liberdade de expressão, inauguram uma nova concepção de educação no estado de Mato Grosso do Sul. Uma educação reinventada que atende às necessidades da sociedade embasada nos valores humanos mais essenciais. Uma educação de direito de todos e dever do Estado.

Tudo isso foi possibilitado pelo processo de imigração dos haitianos, que buscaram novas oportunidades em Campo Grande, MS. Sem eles, o Estado não teria realizado essa ação de promover um curso de Língua Portuguesa para Estrangeiros, ofertado pela Secretaria Estadual de Educação (SED/MS), que cumpre com o papel do Estado em prol da imigração.

Reitera-se que tal prática pode estar alicerçada em dois pontos: o primeiro deles relaciona-se ao número considerável de haitianos residentes na capital de Mato Grosso do Sul; e o segundo, 
às políticas que normatizam a relação humanitária entre Brasil e Haiti. A razão da estadia dos imigrantes em Campo Grande não foi estudada nesta pesquisa, mas pode estar relacionada ao processo de desenvolvimento econômico em que o estado assenta-se nos últimos anos, bem como nas características de produção e renda, tais como: pecuária, cana-de-açúcar e álcool. Dessa forma, a mão de obra não qualificada presente nos imigrantes é propensa a ser utilizada em Mato Grosso do Sul. Reforça-se que essa consideração pode ser fruto de uma nova pesquisa.

Quanto às normativas, alguns instrumentos legais proporcionaram aos haitianos o direito ao conhecimento da língua, a saber: Conselho Nacional de Imigração e Lei da Imigração.

Diante disso, entende-se que a esses imigrantes foram ofertados os direitos à educação estabelecidos na Constituição Brasileira.

Ressalta-se que este foi um primeiro estudo em relação aos haitianos residentes em Campo Grande, MS, suas expectativas, contextos sociais e culturais. Segundo relatos, de 2016 para 2017 novos imigrantes chegaram e outros partiram, a maioria seguiu para o Chile em busca de novas perspectivas. Compreender essas relações e movimentos é imprescindível para a criação de novas políticas públicas que atendam essas pessoas, pois elas precisam ser inseridas na sociedade e mercado de trabalho de maneira justa. Para tanto, novos estudos e acompanhamentos são necessários.

- Nota de esclarecimento: acrescenta-se que, no dia 25 de agosto de 2017, foi publicado em Diário Oficial n. 9.481 a Resolução SED n. 3.320 de 24 de agosto de 2017, que estabelece:

[....] a suspensão do oferecimento dos cursos no Centro Estadual de Línguas e Libras "Professor Fernando Peralta Filho", localizado no município de Campo Grande/MS, e sua Extensão, localizada no município de Dourados/MS, e dá outras providências. A SECRETÁRIA DE ESTADO DE EDUCAÇÃO, no uso das atribuições que the conferem o inciso II, do artigo 93, da Constituição Estadual, o disposto na Lei n. 2.787, de 24 de dezembro de 2003, a Lei n. 4.640, de 24 de dezembro de 2014, e Resolução/SED n. 3.161, de 22 de dezembro de 2016, RESOLVE: Art. 1ㅇ Suspender, temporariamente, a partir de 24 de agosto de 2017, o oferecimento dos cursos no Centro Estadual de Línguas e Libras “Professor Fernando Peralta Filho", localizado no município de Campo Grande/MS, e sua Extensão que funciona nas dependências da Escola Estadual Abigail Borralho, localizada no município de Dourados/ MS. CAMPO GRANDE-MS, 24 DE AGOSTO DE 2017. Grifo nosSo (MATO GROSSO DO SUL, 2017, p. 6).

Mediante a suspensão temporária da oferta de cursos no Centro Estadual de Línguas e Libras "professor Fernando Peralta Filho", posterior a esta pesquisa, cumpre ao Ministério Público acompanhá-los, pois o Brasil, com a nova política de imigração, necessita de meios e mecanismos de inserção humanitária, o qual era proporcionado pelo CEL/MS. Dessa maneira, cabe aos cidadãos averiguar esses encaminhamentos, pois o país precisa de pessoas que venham somar ao crescimento econômico e não de imigrantes que, por falta de conhecimento da língua, vivam em abrigos ou perambulando pelas ruas.

\section{REFERÊNCIAS}

ALMEIDA FILHO, José Carlos Paes (Org.). Formas de credenciamento para atuar profissionalmente na área de EPLE. Campinas: SP, UNICAMP, 2004.

ALTO COMISSARIADO DAS NAÇÕES UNIDAS PARA OS REFUGIADOS (ACNUR). O ACNUR no Brasil. 2005. Disponivel em: <http://www.acnur.org/t3/index.php?id=245\%27A=0>. 
BITTENCOURT, Terezinha. Contribuições da Linguística ao ensino de Português Língua Estrangeira. In: JUDICE, Norimar (Org.). Ensino de português para estrangeiros. Ciclo de Palestras. Niterói, EDUFF, 1997, p. 89-100.

BOURDIEU, Pierre. A economia das trocas linguísticas: o que falar quer dizer. 2. ed. São Paulo: Universidade de São Paulo, 2008.

BRASIL. Presidência da República. Casa Civil. Subchefia para Assuntos Jurídicos. Lei n. 13.445, de 24 de maio de 2017. Institui a Lei de Migração. Brasília, DF. Disponível em: <http://www.planalto.gov.br/ ccivil_03/_ato2015-2018/2017/lei/L13445.htm>.

. Resolução Normativa CNIg n. 97, de 12 de janeiro de 2012. Dispõe sobre a concessão do visto permanente previsto no art. 16 da Lei n. 6.815, de 19 de agosto de 1980, a nacionais do Haiti. Disponível em: <https://www.legisweb.com.br/legislacao/?id=116083>.

. Presidência da República. Casa Civil. Subchefia para Assuntos Jurídicos. Lei n. 11.161, de 5 de agosto de 2005. Dispõe sobre o ensino de língua espanhola. Brasília, DF. Disponível em: <http://www. planalto.gov.br/ccivil_03/_ato2004-2006/2005/lei/l11161.htm>.

. Presidência da República. Casa Civil. Subchefia para Assuntos Jurídicos. Lei n. 9.474, de 22 de julho de 1997. Define mecanismos para a implementação do Estatuto dos Refugiados de 1951, e determina outras providências. Brasília, DF. Disponível em: <http://www.planalto.gov.br/ccivil_03/leis/l9474.htm>.

. Presidência da República. Constituição da República Federativa do Brasil: promulgada em 5 de outubro de 1988. Brasília: Senado Federal, 1988.

CANDAU, V. M. F. Pluralismo cultural, cotidiano escolar e formação de professores. In: CANDAU, V. M. F. (Org.). Magistério: construção cotidiana. Petrópolis, RJ: Vozes, 1997.

CANEN, A. Formação de professores e diversidade cultural. In: CANDAU, V. M. F. (Org.). Magistério: construção cotidiana. Petrópolis, RJ: Vozes, 1997.

. Teacher education and competence in an intercultural perspective: a parallel between Brazil and the UK. Compare, v. 25, n. 3, p. 227-37, 1995.

CARNEIRO, M. L. T. A imagem do imigrante indesejável. Seminários - Imigração, Repressão e Segurança Nacional, São Paulo, n. 3, p. 23-44, out. 2003.

CHARAUDEAU, P. Les conditions de compréhension du sens de discours. In: ENCONTRO FRANCOBRASILEIRO DE ANÁLISE DO DISCURSO, 1. Anais... Rio de Janeiro: CIAD, UFRJ, 1995. Republicado em 2005 In: PAULIUKONIS, M. A.; GAVAZZI, S. (Org.). Da língua ao discurso: reflexões para o ensino. Rio de Janeiro: Lucerna, 2005. p. 11-29.

FEATHERSTONE, M. O desmanche da cultura: globalização, pós-modernismo e identidade. São Paulo: Studio Nobel/Sesc, 1997.

GADOTTI, M. Perspectivas atuais da educação. Porto Alegre, RS: Artes Médicas, 2000.

GOLDENBERG, M. A arte de pesquisar: como fazer pesquisa qualitativa em Ciências Sociais. Rio de Janeiro: Record, 2004.

GRANNIER, D. M. Uma proposta heterodoxa para o ensino de português a falantes de espanhol. In: JUDICE, Norimar (Org.). Português para estrangeiros: perspectives de quem ensina. Niterói, RJ: Intertexto, 2002. p. 57-80.

GRANT, N. D. C. Some problems of identity and education: a comparative examination of multicultural education. Comparative Education, v. 33, n. 1, p. 9-28, mar. 1997.

MATO GROSSO DO SUL. Secretaria de Estado de Educação. Resolução/SED n. 3.320, de 25 de agosto de 2017. Dispõe sobre a suspensão do oferecimento dos cursos no Centro Estadual de Línguas e Libras "Professor Fernando Peralta Filho". Diário Oficial. Campo Grande, 2017.

ORLANDI, E. P. Análise de discurso: princípios e procedimentos. 5. ed. Campinas, SP: Pontes, 2003. 
QUADRO EUROPEU COMUM DE REFERÊNCIA PARA AS LíNGUAS (QECR). Aprendizagem, ensino, avaliação. Porto: Edições Asa, dez. 2001.

ZAMBERLAN, J.; BOCCHI, L.; CORSO, G.; CIMADON, J. Os novos rostos da imigração no Brasil - haitianos no Rio Grande do Sul. Porto Alegre: Solidus, 2014. 81p.

\section{Sobre os autores:}

Andrea Walder Zanatti: Licenciada em Pedagogia e Letras; Mestre em Ensino de Ciências pela Universidade Federal de Mato Grosso do Sul. Técnica Pedagógica de Língua Portuguesa - Divisão de Avaliação - SEMED. E-mail: awzanatti@hotmail.com

José Flávio Rodrigues Siqueira: Graduado em Ciências Biológicas. Especialista em Educação Ambiental; Especialista em Mídias na Educação. Mestre em Educação. Professor efetivo de Ciências/Biologia na rede municipal de ensino de Campo Grande e na rede estadual de Mato Grosso do Sul. E-mail: siqueirajfr@gmail.com

Robson Gonçalves Félix: Doutor em Educação pelo Programa de Pós-Graduação em Educação da Universidade Federal do Mato Grosso do Sul (UFMS). Mestre em Educação pela Universidade Federal de Uberlândia (UFU). Possui formação inicial no curso de Graduação em Educação Física da UFU. Docente efetivo no Instituto Federal de Educação, Ciência e Tecnologia de Mato Grosso do Sul (IFMS).E-mail: robson.felix@ifms.edu.br 